\title{
ARTICLE OPEN \\ Seryl tRNA synthetase cooperates with POT1 to regulate telomere length and cellular senescence
}

\author{
Yingxi $\mathrm{Li}^{1}$, Xiyang $\mathrm{Li}^{1}$, Mei Cao ${ }^{1}$, Yuke Jiang ${ }^{1}$, Jie Yan ${ }^{1}$, Ze Liu ${ }^{1}$, Rongcun Yang ${ }^{1}, \mathrm{Xu} \mathrm{Chen}^{2}$, Peiqing Sun ${ }^{3}$, Rong Xiang ${ }^{1}$, \\ Longlong Wang ${ }^{1,2}$ and Yi Shi $\mathbb{i}^{1,2}$
}

\begin{abstract}
Deregulated telomere length is a causative factor in many physiological and pathological processes, including aging and cancer. Many studies focusing on telomeres have revealed important roles for cooperation between the Shelterin protein complex and telomerase in maintaining telomere length. However, it remains largely unknown whether and how aging-related stresses, such as deregulated protein homeostasis, impact telomere length. Here, we explored the possible roles of aminoacyl tRNA synthetases (AARSs), key enzymes catalyzing the first reactions in protein synthesis, in regulating telomere length and aging. We selected seryl tRNA synthetase (SerRS) since our previous studies discovered expanded functions of SerRS in the nucleus in addition to its canonical cytoplasmic role in protein synthesis. In this study, we revealed that overexpression of SerRS promoted cellular senescence and inhibited the growth of cervical tumor xenografts in mice by triggering the senescence of tumor cells. In the nucleus, SerRS directly bound to telomeric DNA repeats and tethered more POT1 proteins to telomeres through a direct interaction between the UNE-S domain of SerRS and the OB1 domain of POT1. We further demonstrated that SerRS-induced enrichment of POT1 prevented the recruitment of telomerase to telomeres, resulting in progressive telomere shortening. Our data suggested a possible molecular link between protein synthesis and telomere length control, the deregulation of which may be associated with aging and cancer.
\end{abstract}

Signal Transduction and Targeted Therapy (2019)4:50

; https://doi.org/10.1038/s41392-019-0078-1

\section{INTRODUCTION}

Human telomeres comprise tandem repeats of double-stranded TTAGGG repeats that terminate in a single-stranded 3 ' overhang. In human somatic cells, telomere sequence is progressively lost with each cell division, and this shortening may eventually trigger cell senescence. ${ }^{1,2}$ Deregulation of telomere-length maintenance has been observed in cancer and aging. ${ }^{3}$ In stem cells and cancer cells, which are able to maintain telomere length during cell division, a specialized reverse transcriptase named telomerase adds telomeric repeats to the chromosome ends. ${ }^{4}$ Overexpression of telomerase, which is usually not expressed in normal cells, results in an increased incidence of spontaneous cancer in mice. ${ }^{5,6}$ In addition to telomerase, the length of telomeres is also controlled by a telomere complex composed of six proteins, known as Shelterin, which binds to and protects the telomere from activating DNA damage signaling and double-strand break repair pathways.'

As a key protein complex regulating the recruitment of telomerase to telomeres, Shelterin is composed of six proteins, namely, TRF1, TRF2, TIN2, RAP1, POT1, and TPP1. ${ }^{8-10}$ In the Shelterin complex, POT1 is the only protein that binds singlestranded telomeric DNA with high affinity and specificity. ${ }^{11,12}$ This binding is mediated by the two oligonucleotide/oligosaccharide binding folds (OB-folds) of POT1 at the N-terminus, while the C-terminal portion of POT1 binds TPP $1 .{ }^{13}$ Recent studies have indicated that both POT1 and TPP1 are critical factors for the recruitment of telomerase. POT1 has been shown to negatively regulate telomerase engagement. Depletion of POT1 or overexpression of OB1-truncated POT1 causes rapid telomerasedependent telomere elongation. ${ }^{14}$ TPP1 can directly interact with telomerase through a protein surface termed the TEL patch. ${ }^{15}$ Cells lacking the TPP1/telomerase interaction undergo progressive telomere shortening. ${ }^{16,17}$ However, it remains largely unknown whether there are other regulators that bridge aging-related intrinsic and extrinsic stimuli to control telomere length.

Protein synthesis has been shown to affect lifespan. Many mutations in or depletions of the translational machinery were found to impact the lifespan of various organisms. ${ }^{18-21}$ However, how altered translation machinery affects lifespan is not fully understood. The nutrient-responsive target of rapamycin (TOR) signaling pathway, which has a conserved role in modulating longevity, has distinct roles in regulating translation initiation and elongation. ${ }^{22-25}$ As a key family of enzymes that catalyze the first reaction in protein synthesis, namely, adding amino acids to specific tRNAs, aminoacyl tRNA synthetases (AARSs) gained many new domains during evolution, expanding their functions beyond translation. ${ }^{26}$ Interestingly, some members, such as leucyl tRNA synthetase (LeuRS), have been reported to mediate the amino acid signals to the TOR pathway. ${ }^{27}$ We were specifically interested in another member, i.e., seryl tRNA synthetase (SerRS). Our previous

\footnotetext{
${ }^{1}$ School of Medicine, Nankai University, 94 Weijin Road, Tianjin 300071, China; ${ }^{2}$ Tianjin Key Laboratory Human Development and Reproductive Regulation, Nankai University

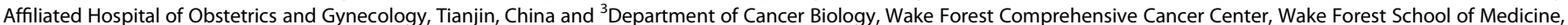
Winston-Salem, NC, USA

Correspondence: Longlong Wang (wangl@nankai.edu.cn) or Yi Shi (yishi@nankai.edu.cn)
}

Received: 5 March 2019 Revised: 4 April 2019 Accepted: 23 April 2019

Published online: 29 November 2019 
studies have shown that vertebrate SerRS acquired a C-terminal domain unique to SerRS (namely, the UNE-S domain), which harbors a nuclear localization signal (NLS) and may divert a portion of SerRS proteins into the nucleus. ${ }^{28}$ Nuclear SerRS can directly bind the promoter of VEGFA, suppressing its transcription and therefore inhibiting angiogenesis. ${ }^{29-31}$ Our unpublished chromatin immunoprecipitation (ChIP) data suggested that SerRS may bind more DNA loci on regions of chromosomes, including telomeres. Here, we explored the impact of SerRS on cellular senescence and investigated the underlying SerRS-mediated regulation of telomere length through its interaction with telomeric DNA and Shelterin proteins.

\section{RESULTS}

Nuclear SerRS decreases the length of telomeres and promotes cellular senescence

It has been reported that the rate of protein synthesis decreases during cellular aging due to the declined efficiency of the components in the protein synthetic machinery, including ribosomes and elongation factors. ${ }^{18}$ However, as the key enzymes catalyzing the first reaction in protein synthesis, i.e., adding amino acids to their cognate tRNAs, the role of AARSs in aging remains largely unknown. To obtain insights into this question, we studied one AARS, SerRS, to test whether AARSs regulates cellular senescence. We overexpressed SerRS in normal fibroblasts, BJ cells, and in a HeLa cell strain, HeLa 1.2.11, which harbors long telomere repeats $(\sim 20 \mathrm{~kb})$. We observed an unexpected increase in SA- $\beta$-gal activity (Fig. $1 \mathrm{a}, \mathrm{b}$ ) and increased levels of cellular senescence signaling molecules, such as P21, P16, and $\beta$-galactosidase $(\beta-G a l)^{32-34}$ at late cell passages of both cells (Fig. 1c); these changes were even observed in HeLa 1.2.11 cells, which undergo little replicative senescence (Fig. 1b), suggesting a role of SerRS in promoting cellular senescence beyond its role in translation. Our previous studies have shown that in addition to its canonical function in protein biosynthesis, vertebrate SerRS evolved a noncanonical nuclear function to directly bind DNA and regulate the transcription of target genes involved in angiogenesis. ${ }^{28}$ We hypothesized that nuclear SerRS might promote cellular senescence. Given that telomere length control is a key event that triggers cellular senescence, we first examined the correlation between nuclear SerRS and telomere length.

We chose two strains of telomerase-positive HeLa cells that differ in telomere length, i.e., HeLa VST (for Very Short Telomeres) cells with an average telomere length of $\sim 5 \mathrm{~kb}$ and HeLa 1.2.11 cells, which have longer telomeres $(\sim 20 \mathrm{~kb})$. We observed similar levels of cytoplasmic SerRS proteins in both cells (Fig. 1d). However, as reported, ${ }^{28}$ we observed $\sim 10 \%$ SerRS proteins in the nucleus of HeLa VST cells, while there were much lower levels of nuclear SerRS proteins in HeLa 1.2.11 cells (Fig. 1d). These results were further confirmed by immunofluorescent staining and confocal microscopy (Fig. 1e, f), suggesting that the different lengths of telomeres in these two cell strains may relate to the difference in levels of nuclear SerRS.

To further investigate whether nuclear SerRS regulated the length of telomeres, we established a stable SerRS-overexpressing HeLa 1.2.11 cell strain that showed increased SerRS expression in both the nucleus and the cytoplasm (Fig. 1g). We continuously passaged the cells for 45 population doublings (PD). Strikingly, the telomere length detected by Telomere Restriction Fragment (TRF) analysis showed a progressive reduction (from $\sim 16 \mathrm{~kb}$ to $\sim 9 \mathrm{~kb}$ ) in SerRS-overexpressing HeLa 1.2.11 cells when compared with empty vector transfected cells, which showed almost no change in the length of telomere (Fig. $1 \mathrm{~h}, \mathrm{i}$ ). The telomere length was also examined by the metaphase chromosome spreads followed by a telomeric quantitative fluorescent in situ hybridization (Q-FISH) assay (Fig. 1j, k). Significant telomere shortening was viewed by reduced FISH signals, further indicating that telomeres were globally shortened when SerRS was overexpressed. Consistently, we also observed a significant increase in the appearance of telomere-free chromosome ends, which is also indicative of telomere shortening, in SerRS-overexpressing cells (Fig. 1I).

Taken together, these results suggest that nuclear SerRS negatively regulated telomere length and thus led to cellular senescence.

SerRS induces tumor cell senescence to inhibit the growth of cervical cancer xenografts in mice, and its expression correlates with better prognosis in cancer patients

Tumors require the active biosynthesis of macromolecules, including proteins, to fuel tumor cell growth and proliferation. We analyzed the correlation between the levels of AARSs and the relapse-free survival (RFS) of breast cancer patients in previously generated microarray data sets from 1764 breast cancer patients. ${ }^{35}$ As expected, high expression of many AARS members tightly correlated with a poor prognosis of cancer patients (Fig. 2a). Other AARS family members, except SerRS, showed no such tight correlation (Supplementary Fig. 1). In contrast, high expression of SerRS shows a very tight correlation with better prognosis of cancer patients (Fig. 2a), suggesting a novel role of SerRS in addition to protein biosynthesis in suppressing tumor progression. Consistently, we observed that the overexpression of SerRS induced the senescence of HeLa cells (Fig. 1b, c). These results further supported an important function of SerRS in balancing protein synthesis and telomere shortening-induced cellular senescence to prevent the malignant proliferation of cells.

To further test whether SerRS could suppress tumor progression in vivo, we used a tumor xenograft system; HeLa cells that were stably transfected with SerRS or an empty vector were xenografted into immune-deficient mice and monitored. Overexpression of SerRS in HeLa cells dramatically inhibited the growth of the tumor xenograft (Fig. 2b, c). The levels of the senescence molecular markers $\beta$-Gal, P21, and P16 were significantly increased in SerRS-overexpressing tumor cells in the tumor xenografts (Fig. 2d, e), suggesting that a high level of SerRS was able to induce the senescence of tumor cells, which led to the inhibited growth of tumor xenografts in mice. Taken together, the in vivo data further confirmed that SerRS may function as a tumor suppressor by promoting cellular senescence.

SerRS directly binds telomeric repeats

Next, we explored how SerRS regulated the length of telomeres. We first investigated whether nuclear SerRS was able to bind to telomeres directly. The colocalization of SerRS with telomeres was examined by immunofluorescent staining for SerRS and FISH for telomeres in HeLa cells. We found that in the nucleus of HeLa VST cells, in addition to binding the promoters of target genes such as VEGFA, ${ }^{29}$ there was a portion of SerRS protein that localized to telomeres, whereas in HeLa 1.2.11 cells, there was much less SerRS protein in the nucleus (Fig. 3a, b). To further confirm the binding of SerRS to telomeres, Flag-tagged SerRS or Flag-tagged Shelterin TRF1 (as a positive control) was transfected into HeLa 1.2.11 cells (Fig. 3c). ChIP assays were performed with nuclear extracts using an anti-Flag antibody or a negative control IgG. The precipitated DNA fragments were then hybridized with a digoxin-labeled telomere-specific probe. As shown in Fig. 3d, the SerRS antibody coprecipitated telomere DNA fragments, as did the TRF1 antibody, suggesting the binding of SerRS to telomeres.

Given the capacity of SerRS to directly interact with DNA, ${ }^{29}$ we next examined whether SerRS directly interacted with telomeric DNA repeats. Using an electrophoretic mobility shift assay (EMSA) with purified recombinant SerRS protein, we found that SerRS specifically bound telomeric repeats and its known 
a
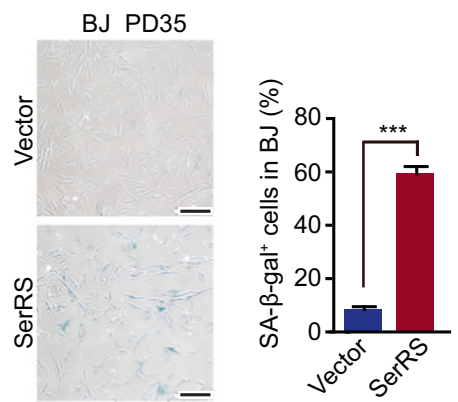

b

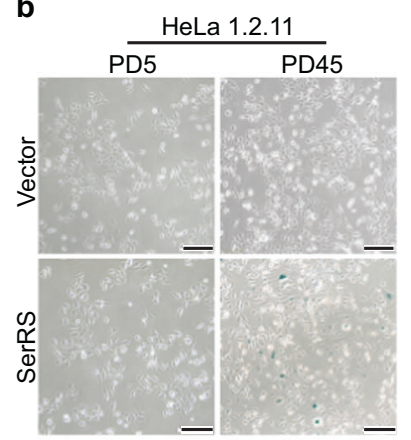

h

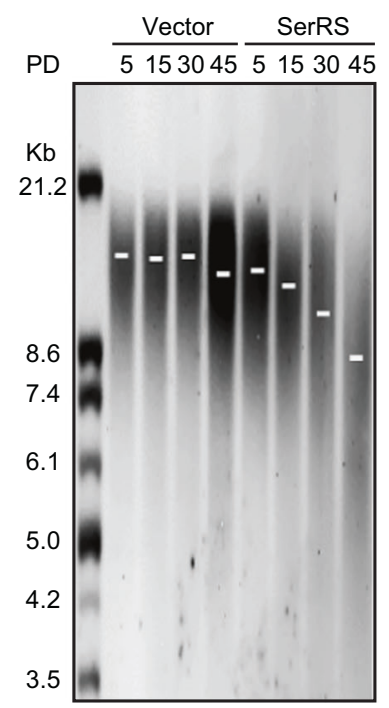

C

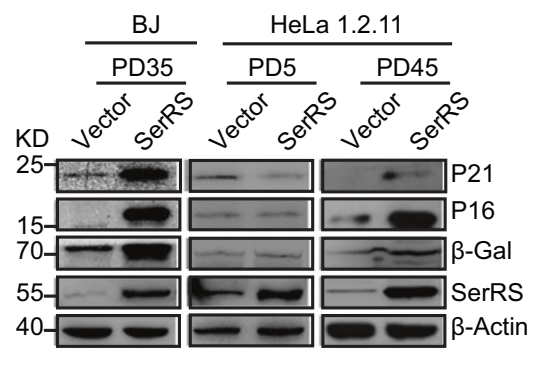

d

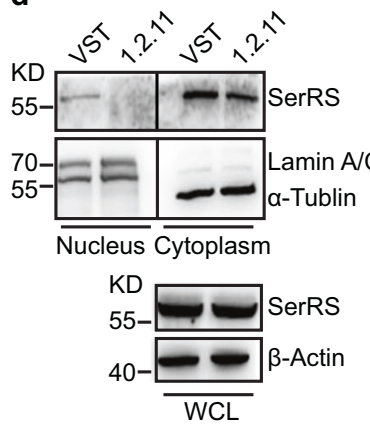

e

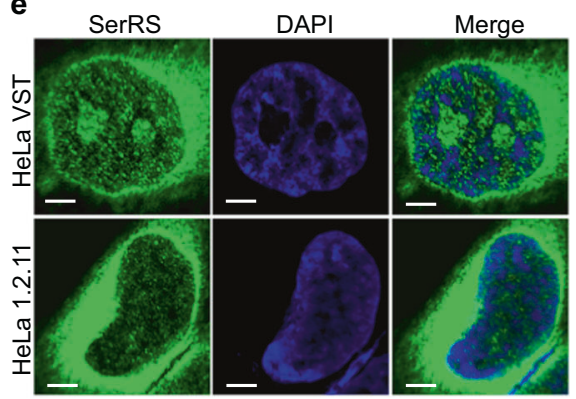

f
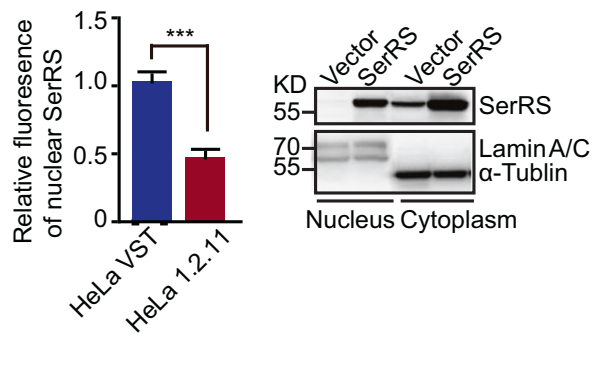

j

i

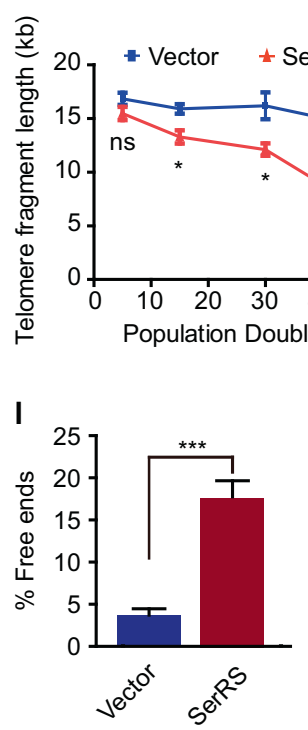

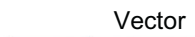
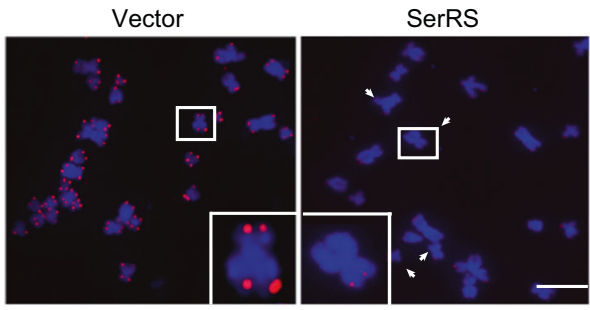

k

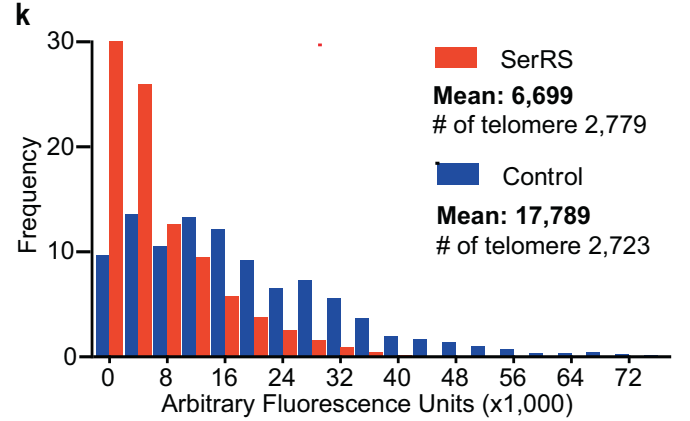

DNA-binding sequence from the VEGFA promoter, ${ }^{29}$ whereas there was no binding of SerRS with a random DNA sequence (Fig. 3e). Thus, SerRS could bind the telomere through direct interaction with telomeric DNA repeats.

\section{SerRS directly interacts with Shelterin POT1}

The Shelterin complex has been shown to cooperate with telomerase to maintain telomere length homeostasis. ${ }^{36}$ Among the six proteins in Shelterin, POT1 was reported to bind a singlestranded telomere $3^{\prime}$ overhang via its $\mathrm{N}$-terminal $\mathrm{OB}$ fold and therefore inhibit the recruitment of telomerase. Depletion of POT1 leads to rapid elongation of telomeres in telomerase-positive cells. ${ }^{37}$ In a high-throughput protein-protein interaction screening for Shelterin-associated proteins, SerRS was identified as a candidate protein that may interact with POT1. ${ }^{38}$
To confirm the interaction between SerRS and POT1, we first examined the localization of these two proteins in HeLa VST cells. SerRS was partially colocalized with POT1 in the nucleus (Fig. 4a). The interaction between SerRS and POT1 was further confirmed by their Co-IP from HeLa cells. As shown in Fig. 4b, V5-tagged POT1 was able to be coprecipitated with Flag-tagged SerRS via Flag antibody-mediated isolation; the reverse experiment with a V5 antibody produced a complementary result. In HeLa VST cells, the endogenous SerRS proteins could be coprecipitated with endogenous POT1 by POT1 antibody (Fig. 4c). Taken together, these results strongly suggested that SerRS interacted with POT1 in the nucleus.

To examine whether SerRS directly interacts with POT1, we purified recombinant POT1 with a His6 tag at its C-terminal end and recombinant GST-fused SerRS proteins. The GST pull-down 
Fig. 1 Nuclear SerRS promotes cellular senescence and telomere shortening. a SA- $\beta$-gal activity determined by X-gal staining in 35 population doublings (PD35) of BJ cells stably transfected with SerRS (SerRS) or empty vector (Vector). Scale bars represent $100 \mu \mathrm{m}$. Quantification of the percentage of SA- $\beta$-gal positive cells $\left(\mathrm{SA}-\beta\right.$-gal ${ }^{+}$cells) is shown in the right panel. Data are represented as the means \pm SEM $(n=10)$. ${ }^{* * *} P<$ 0.001 , two-tailed Student's $t$-test. b SA- $\beta$-gal activity assay on different PDs of HeLa 1.2.11 cells stably transfected with SerRS or empty vector. Quantification of the percentages of SA- $\beta-$ gal ${ }^{+}$cells is shown in the right panel (means $\pm \mathrm{SEM}, n=10,{ }^{* *} P<0.01$, two-tailed Student's $t$-test). c Immunoblot showing the levels of markers of cellular senescence in BJ or HeLa 1.2.11 stable cells at the indicated PDs. $\mathbf{d}$ The protein levels of SerRS in the cytoplasmic and nuclear fractions extracted from HeLa cells with very short telomeres (VST) or long telomeres (1.2.11) were analyzed by immunoblot. Lamin A/C and $\alpha$-tubulin served as nuclear and cytoplasmic markers, respectively. WCL, whole cell lysate. e Nuclear SerRS proteins in HeLa VST and HeLa 1.2.11 are shown by immunofluorescent staining. Scale bars represent $5 \mu \mathrm{m}$. f Quantification of the relative levels of nuclear SerRS protein shown in (e). Data are represented as the means \pm SEM $(n=10) .{ }^{* *} P<0.001$, two-tailed Student's t-test. $\mathbf{g}$ Immunoblot to show the levels of SerRS proteins in the cytoplasmic and nuclear fractions of indicated HeLa 1.2.11 stable cells. $\mathbf{h}$ HeLa 1.2.11 cells stably transfected with the SerRS expression vector or the empty vector were continuously passaged for the indicated PDs. The telomere lengths were examined by telomere restriction fragment (TRF) analysis. $\mathbf{i}$ The average telomere lengths from $\mathbf{h}$ were quantified by GelPro analysis software. Data are represented as the means \pm SEM $(n=3)$. ${ }^{*} P<0.05,{ }^{*} P<0.01$, two-tailed Student's $t$-test. $\mathbf{j}$ Representative images of the telomeres from metaphase chromosomes in indicated HeLa 1.2.11 cells analyzed by Q-FISH assay using a telomeric Cy3-(CCCTAA) ${ }_{3}$ PNA probe (red). Signal-free ends are indicated by arrows. Insets are magnified examples of individual chromosome. $\mathbf{k}$ Q-FISH images in $\mathbf{j}$ were quantified by TFL-TELO software. The distributions of individual telomeres with different lengths, which are represented by arbitrary fluorescence units, from a total of 20 metaphase cells per treatment were displayed. I Quantification of chromosome ends lacking a detectable telomeric signal in $\mathbf{j}$, which is indicative of telomere shortening. Data are shown as the means \pm SEM $(n=15)$ from three independent experiments. ${ }^{* *} P<0.001$, two-tailed Student's $t$-test

assay clearly showed the direct interaction between SerRS and POT1 (Fig. 4d). Further domain mapping showed that SerRS interacts with POT1 through the UNE-S domain (Fig. 4d), which harbors an NLS that was appended to vertebrate SerRS during evolution. $^{28}$ Our domain mapping assay also showed that POT1 bound to SerRS through its OB1 domain (Fig. 4e), through which POT1 bound to single-stranded telomere DNA. ${ }^{39}$

Taken together, these results suggest that SerRS directly interacts with POT1 in the nucleus and may regulate telomere length through POT1.

\section{SerRS tethers more POT1 to telomeres}

Next, we determined whether SerRS could influence the recruitment of POT1 to telomeres, given that SerRS can directly bind telomeric DNA repeats and can interact with POT1 via the UNE-S domain, which is not involved in DNA interaction. ${ }^{28}$ To address this question, we overexpressed V5-tagged SerRS in HeLa 1.2.11 cells, which had a very low level of endogenous SerRS in the nucleus. We observed an enrichment of POT1 on telomeric DNA, as detected by a ChIP assay that was compared with empty vector-transfected cells (Fig. 5a, b); however, overexpression of SerRS did not change the expression of POT1 (Fig. 5c). To confirm these findings, we also examined POT1 localization at telomeres by IF and FISH staining in HeLa 1.2.11 cells transfected with the SerRS vector or the empty vector. As shown in Fig. 5d, POT1 showed significantly increased recruitment to telomeres in SerRSoverexpressing cells. Quantitative analysis indicated that the average percentage of POT1-associated telomere foci was approximately $55.3 \%$ in SerRS-overexpressing cells, which was much more than what was observed in control cells ( 30\%) (Fig. 5e). Additionally, a higher number of cells showed increased POT1associated telomeres upon SerRS overexpression (Fig. 5f). Thus, nuclear SerRS can tether more POT1 protein to telomeric DNA.

SerRS prevents the recruitment of telomerase to telomeric DNA POT1 has been reported to regulate the accessibility of telomerase to telomeric DNA through DNA binding competition. ${ }^{40}$ We next investigated whether POT1 tethered on telomeric DNA by SerRS can prevent the recruitment of telomerase. To test this hypothesis, we utilized FISH assays to detect the abundance of telomerase on telomeres via hybridizing the RNA component of telomerase, i.e., $\mathrm{TERC}^{41}$ while the telomeres were counterstained by immunofluorescent staining of the Shelterin complex protein TRF1. HeLa 1.2.11 cells were transfected with the SerRS expression vector or an empty vector and then synchronized at the S phase, when telomerases are recruited to telomeres. ${ }^{42}$ We observed that overexpression of SerRS resulted in fewer telomerases being recruited to the telomeres (Fig. 6a, b). These data suggested that SerRS promoted the recruitment of POT1 to the telomere, blocking the access of the telomerase.

In summary, our data revealed a noncanonical role of SerRS in controlling telomere length. Once SerRS enters the nucleus, it can directly bind telomeric DNA repeats and tether more POT1 protein on telomeres, which prevents the engagement of telomerase, resulting in progressive telomere shortening and cellular senescence, thus leading to tumor suppression (Fig. 6c).

\section{DISCUSSION}

During evolution, AARSs gained many new domains and expanded their functions beyond their canonical functions in protein biosynthesis. ${ }^{26}$ These expanded functions make AARSs a good bridge between protein homeostasis (proteostasis) and other cellular and biological processes, such as cellular senescence and aging. Many recent studies revealed that some AARS members regulate longevity-related pathways. As a well-known example, LeuRS has been shown to regulate the amino acid signal in conserved mTORC1 signaling that is a well established major regulator of lifespan. ${ }^{43}$ Here, we revealed another mechanism through which AARSs can regulate cellular senescence through direct regulation of telomere length. We revealed that nuclear SerRS directly binds to telomeric DNA repeats and recruits POT1 protein to the telomere, which prevents the engagement of telomerase, and results in progressive telomere shortening and cellular senescence.

UNE-S is a unique domain at the carboxyl-terminus of SerRS in all vertebrates, from fish to humans. ${ }^{44}$ Our previous studies have revealed that the UNE-S domain harbors a robust NLS, which directs SerRS into the nucleus where it participates in vascular development. ${ }^{28}$ Here, we discovered a novel role for the UNE-S domain in the interaction with the Shelterin protein POT1, which is able to trigger telomere shortening and senescence. This result indicates more complicated biological roles were conferred to SerRS during evolution by the acquisition of a multifunctional domain.

As a member of the Shelterin complex, POT1 binds singlestranded telomeric DNA with high affinity and specificity. ${ }^{39}$ This binding is mediated by the two OB domains of POT1 at the $\mathrm{N}$-terminal end of the protein. ${ }^{45}$ The domain mapping analysis showed that the OB1 domain of POT1 was required for SerRS to interact with POT1. Previous studies showed that overexpression of OB1-deleted POT1 (POT1- $\triangle \mathrm{OB}$ ) resulted in rapid telomere elongation, highlighting the important role of OB1 in POT1mediated telomere length control. ${ }^{14}$ According to our results, 

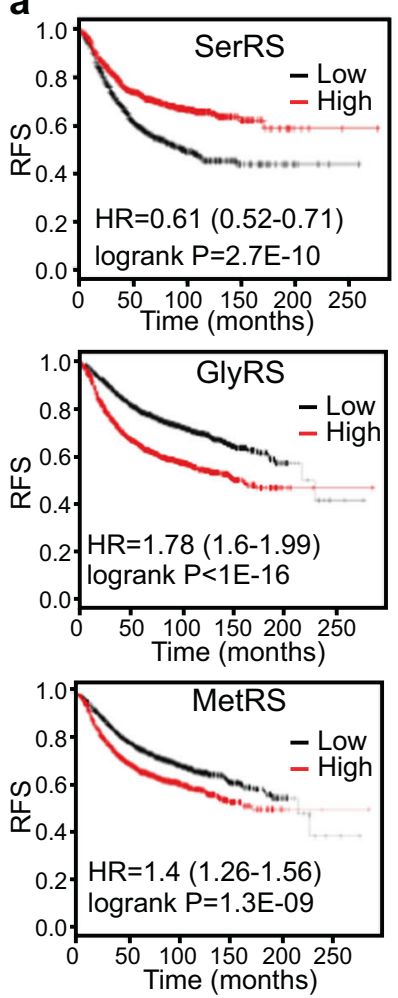

b

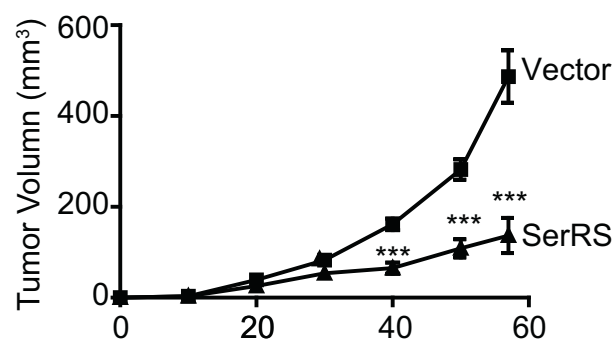

C

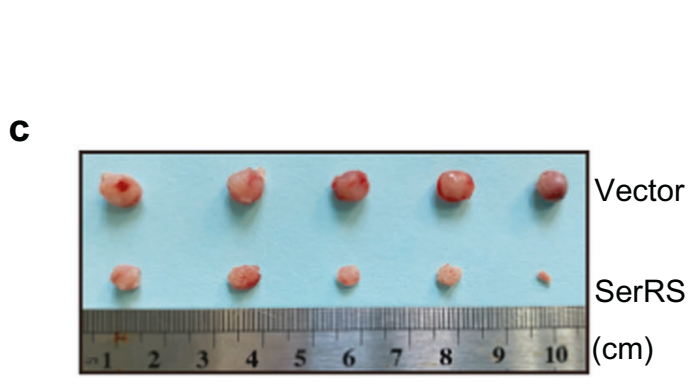

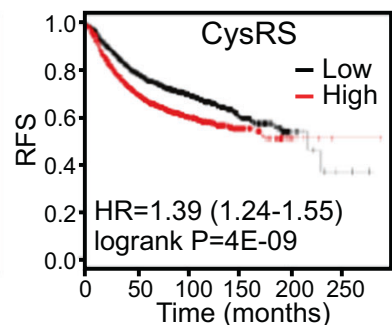
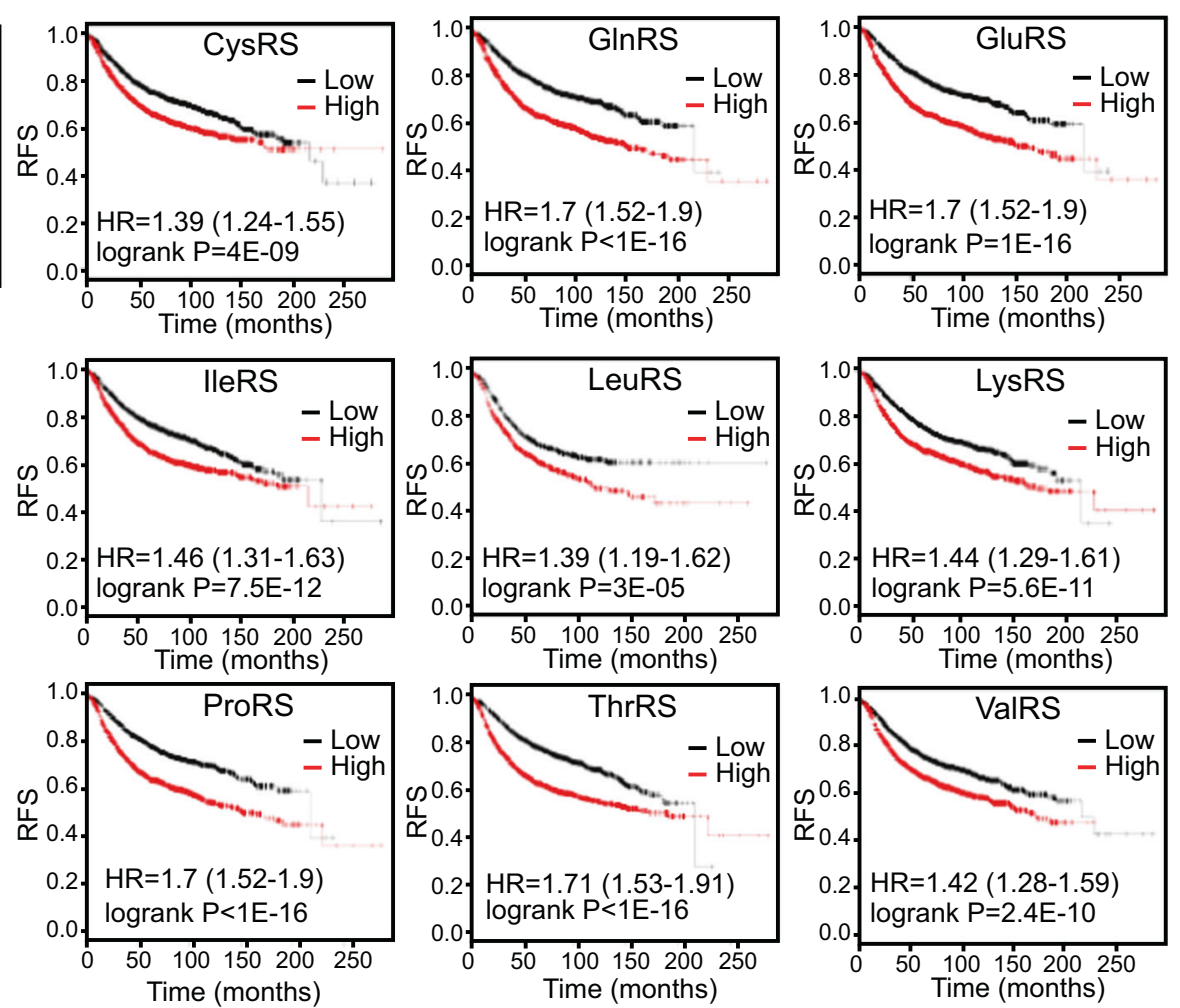

d

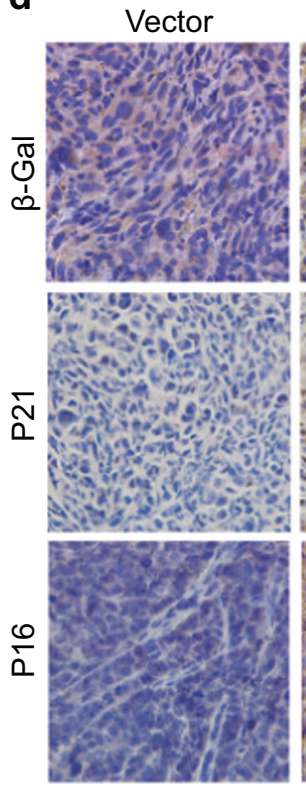

SerRS

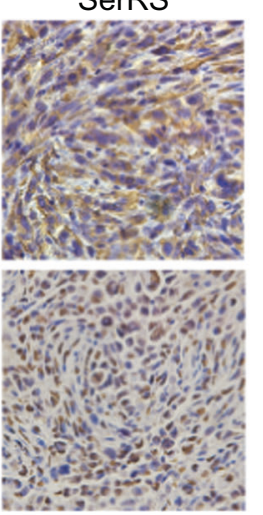

e
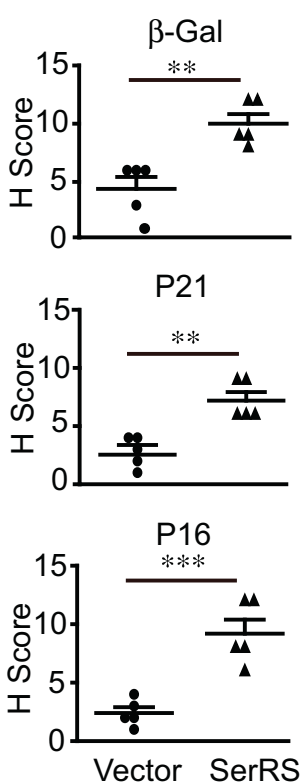

Fig. 2 SerRS functions as a tumor suppressor and correlates with better prognosis of cancer patients. a Kaplan-Meier plots and hazard ratio analysis of human tRNA synthetases reveal a tight correlation with relapse-free survival (RFS) of breast cancer patients. Patient samples were divided into two halves as "low-expression" (black)" and "high-expression" (red) sets for each tRNA synthetase in the analysis ( $\mathrm{n}=1764)$. b, c HeLa cells stably transfected with the SerRS expression vector or the empty vector were injected subcutaneously into NOD/SCID mice ( $n=5$ in each group), and the growth curves of the tumor xenograft were monitored $\mathbf{b}$ (***P<0.001, two-tailed Student's $t$-test). The dissected tumor xenografts are shown in c. d, e Immunohistochemistry analysis of $\beta$-Gal, P21 and P16 to show cellular senescence in the indicated xenografts $\mathbf{d}$, and the protein levels were quantified based on the $\mathrm{H}$-score $\left.\mathbf{e}{ }^{* *} p<0.01,{ }^{* * *} p<0.001\right)$

SerRS may also be involved in this process. However, it is still unknown how the SerRS-POT1 interaction cooperates with the POT1-TPP1 interaction to regulate telomere length homeostasis. It is also unknown how proteostasis stress alters SerRS nuclear import and therefore regulates telomere length.

\section{MATERIALS AND METHODS}

\section{Cell culture}

HeLa 1.2.11, HeLa VST and 293T cells were cultured in Dulbecco's modified Eagle's medium (DMEM) with $4.5 \mathrm{~g} / \mathrm{L}$ glucose (Biological Industries, Israel), supplemented with $10 \%$ fetal bovine serum 


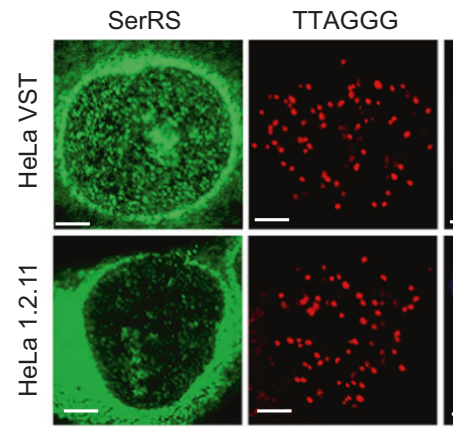

d

b

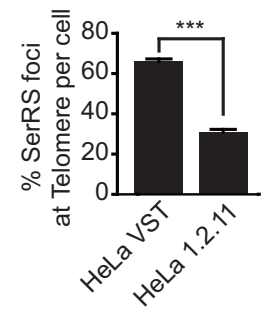

C

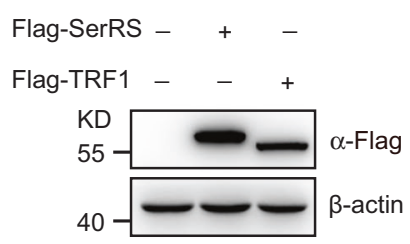

Flag-SerRS - + -
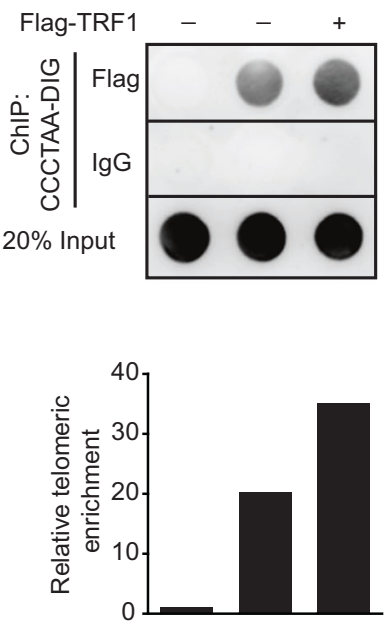

DAPI

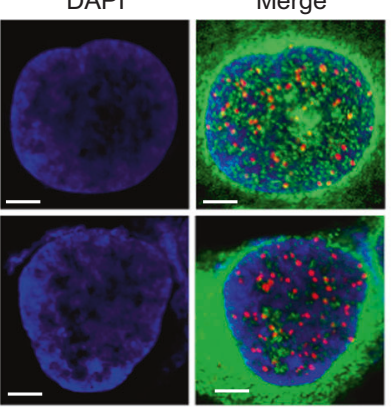

e

DNA probe Control Telomere VEGFA

GAGATC TTAGGG promoter
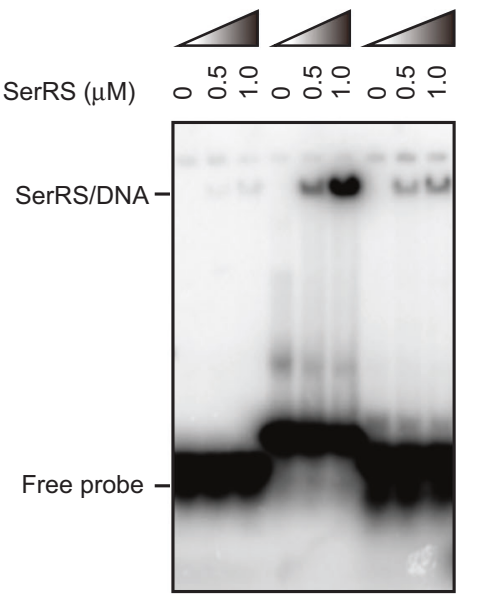

Fig. 3 SerRS binds telomeres by direct interaction with telomeric DNA. a SerRS (green) and telomeres (red) in HeLa VST cells were visualized by immunofluorescent staining and FISH, respectively. Scale bars represent $5 \mu \mathrm{m}$. $\mathbf{b}$ Quantification of the data shown in a to show the percentage of SerRS-associated telomeric foci per cell. Data are represented as the means \pm SEM $(n=20)$. ${ }^{* * *} P<0.001$, two-tailed Student's $t$-test. c, d Flag-tagged SerRS (Flag-SerRS) or Flag-tagged TRF1 (positive control) was ectopically expressed in HeLa 1.2.11 cells c. SerRS and TRF1-associated telomeric DNA fragments were immunoprecipitated with anti-Flag antibody or control IgG and analyzed by dot-blots with DIG-labeled (CCCTAA) 6 probes (d, upper panel). The dot signals were quantified (d, lower panel). e EMSA to determine the direct binding between SerRS and telomeric DNA

(FBS) (Biological Industries), $100 \mathrm{U} / \mathrm{mL}$ penicillin and $100 \mathrm{mg} / \mathrm{mL}$ streptomycin (Gibco, Grand Island, NY, USA) at $37^{\circ} \mathrm{C}$ and $5 \% \mathrm{CO}_{2}$. BJ cells were kindly provided by Peiqing Sun and cultured in EMEM supplemented with $10 \% \mathrm{FBS}, 100 \mathrm{U} / \mathrm{mL}$ penicillin and $100 \mathrm{mg} / \mathrm{mL}$ streptomycin.

\section{Tumor xenograft and immunohistochemistry}

HeLa cells $\left(6 \times 10^{6}\right.$ cells) stably expressing SerRS or stably transfected with an empty vector were injected subcutaneously into six-week-old female NOD/SCID mice to establish a mouse cervical cancer xenograft model. Tumor volumes were determined by measuring the length and width of the xenografts with a Vernier caliper and calculated using the formula (length $\times$ width ${ }^{2}$ )/ 2. When mice were sacrificed, tumor xenografts from each mouse were dissected and used for further analyses. The sections of xenografts were stained with an anti-P21 antibody (Proteintech, China) at a 1:50 dilution, an anti-P16 antibody (Proteintech, China) at a 1:50 dilution and an anti- $\beta$-gal antibody (Proteintech, China) at a 1:50 dilution. After washing the samples, they were incubated with biotin-conjugated secondary antibodies, which was followed by incubation with streptavidin-HRP; finally, they were visualized with a 3,3'-diaminobenzidine (DAB) substrate (ZSGB BIO, Beijing, China). Images were taken using an Olympus microscope (Olympus, Tokyo, Japan). The H-score was used to quantify P21, $\mathrm{P} 16$ and $\beta$-gal expression in tumor tissues, which was calculated by multiplying the staining area (scored as 1, 2, 3 and 4; 1 for $0-25 \%$, 2 for $25 \%-50 \%, 3$ for $50 \%-75 \%$, and 4 for $75 \%-100 \%$ positively stained areas) with the staining intensity (negative, weak, moderate and strong were scored as 1, 2, 3, and 4 based on color density, respectively). Student's $t$-tests were performed for statistical analysis.

Plasmids

For the construction of the pFLAG-SerRS, pFLAG-TRF1 and pcDNA6c-POT1 plasmids, human SerRS, TRF1 and POT1 genes were cloned from HEK293T cells by RT-PCR and inserted into the pFLAG-CMV2 vector (Sigma-Aldrich, St Louis, MO, USA) or the pCDNA6c vector (Thermo-Fisher Scientific, Waltham, MA, USA). For purifying recombinant SerRS and POT1, the coding sequences for SerRS and POT1 were subcloned into both the pET20b vector (Merck, Temecula, CA, USA) and the pGEX-6p-1 vector (GE Healthcare Bio-Sciences, Uppsala, Sweden).

Analysis of senescence-associated beta-galactosidase (SA- $\beta$-gal) activity

The activity of SA- $\beta$-gal in SerRS-overexpressing BJ cells was determined using 5-bromo-4-chloro-3-indolyl P3-D-galactoside (X-gal) following the protocol described in a kit (Beyotime, China). SA- $\beta$-gal-positive cells were counted under a microscope and expressed as the \% of total cells. 
a

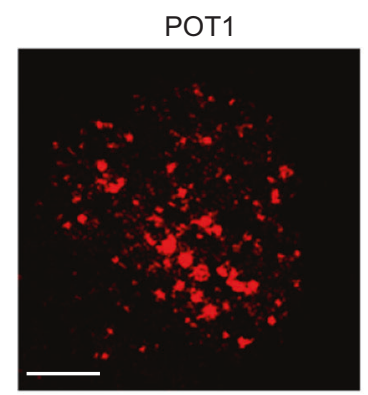

b

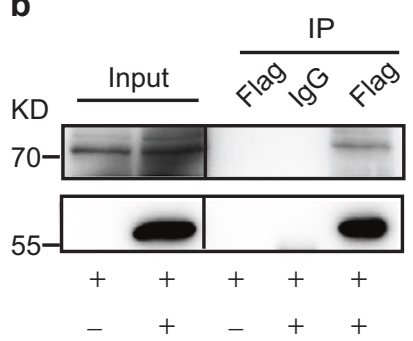

d
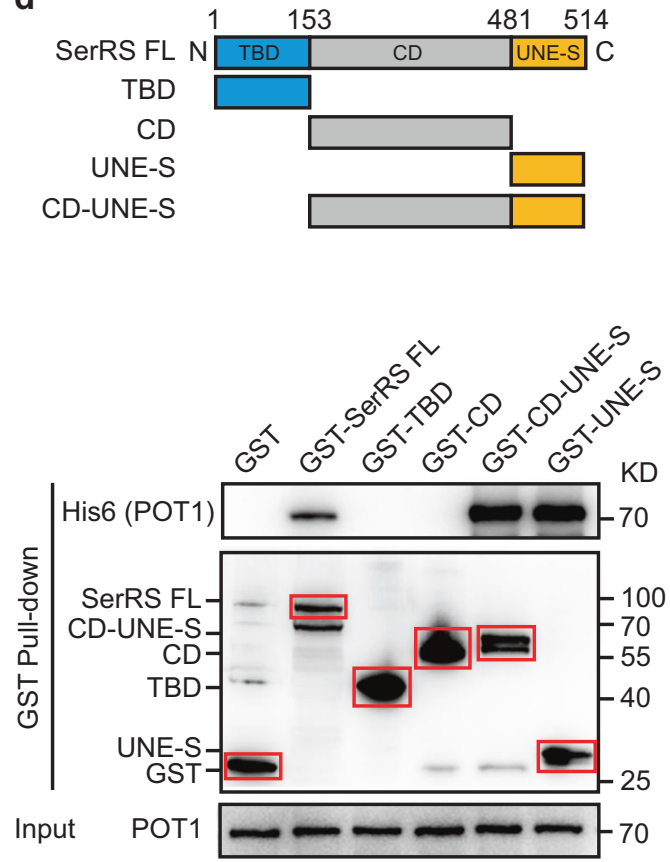

SerRS

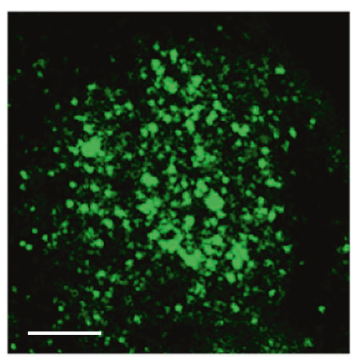

DAPI

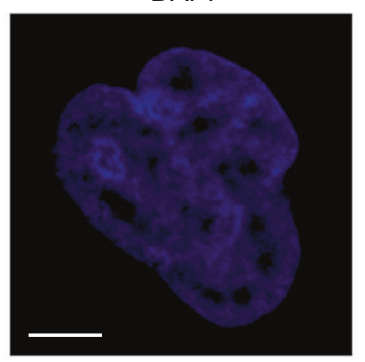

Merge

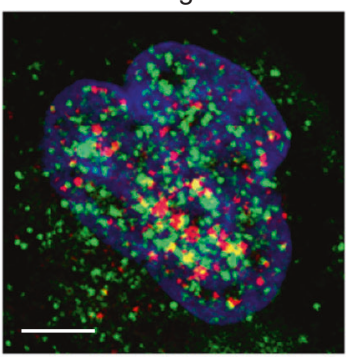

C

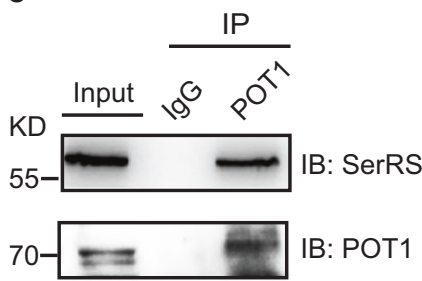

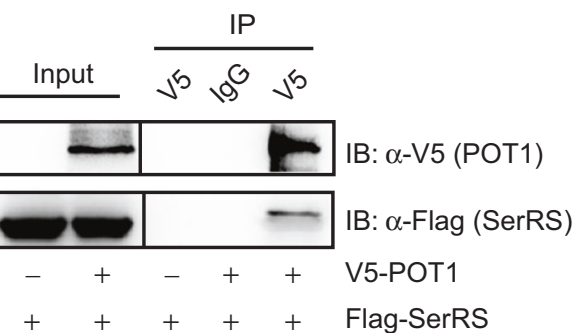

e

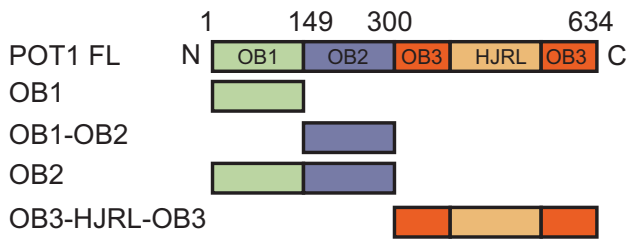

4 SerRS directly interacts with Shelterin POT1 a Immunofluorescent staining to show the colocalization of SerRS (green) and POT1 (red) in the nucleus of HeLa VST cells. Scale bars represent $5 \mu \mathrm{m}$. b Flag-tagged SerRS (Flag-SerRS) and V5-tagged POT1 (V5-POT1) vectors were transfected into HeLa cells, and immunoprecipitation (IP) was performed with the indicated antibodies. Cell lysates and immunoprecipitated proteins were analyzed by immunoblotting (IB) with the indicated antibodies. c HeLa VST cell lysates were immunoprecipitated with a POT1 antibody or a nonspecific lgG and analyzed by immunoblotting with the indicated antibodies. d A GST tag was fused with full length (FL) SerRS or the tRNA-binding domain (TBD), catalytic domain (CD) and unique to SerRS domain (UNE-S) of SerRS (upper panel). The GST-fused SerRS proteins were used to pull down purified His6-tagged POT1, and they were analyzed by immunoblot with anti-His6 antibody and antiGST antibody (lower panel). e GST pull-down assays showed the direct interaction between SerRS and different domains of POT1. Full-length (FL) POT1 and its domains were fused with GST at the N-terminus to pull down purified His6-tagged SerRS. OB1, OB2 and OB3 stand for oligonucleotide/oligosaccharide DNA-binding domains 1, 2, and 3; HJR stands for Holliday junction resolvase-like domains

Nuclear fractionation analysis

Nuclear fractionation was carried out as previously described by $\mathrm{Xu}$ et al. ${ }^{28}$ Cells were harvested after $24 \mathrm{~h}$, and the cytoplasmic and nuclear fractions were separated and extracted by using a NE-PER Nuclear and Cytoplasmic Extraction Kit (Thermo-Fisher Scientific). SerRS was detected with an anti-SerRS antibody (made in our lab). An anti-Lamin A/C antibody (Cell Signaling Technology, Danvers, MA, USA) and an a-tubulin antibody
(Proteintech, China) were used to identify nuclear and cytoplasmic markers, respectively.

Telomere restriction fragment analysis by Southern blot The telomere restriction fragment (TRF) analysis was performed using a TeloTAGGG Telomere Length Assay kit (Roche Life Science, Switzerland) with slight modifications. Briefly, $2 \mu \mathrm{g}$ of genomic DNA was extracted from HeLa cells using a DNeasy Blood \& Tissue 
a

$\begin{array}{llllll}\text { Flag-POT1 } & + & + & + & + \\ \text { V5-SerRS } & - & + & - & +\end{array}$
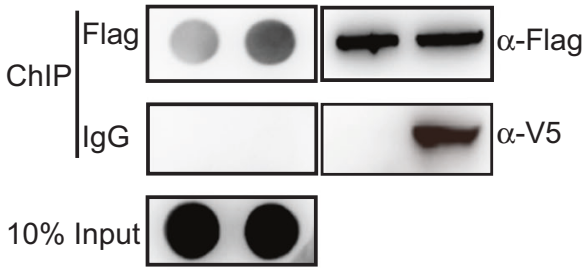

ChIP: CCCTAA-DIG WB b

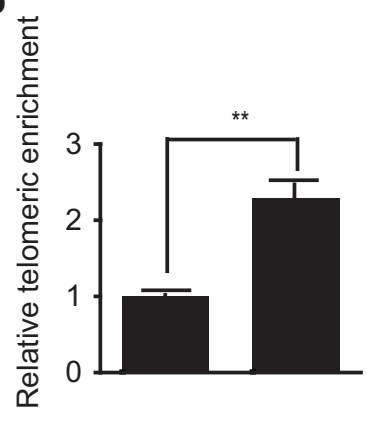

C

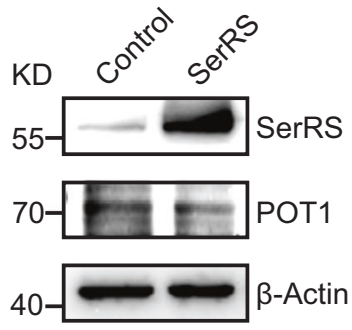

Flag-POT1 $+\quad+$

V5-SerRS - $\quad+$

d
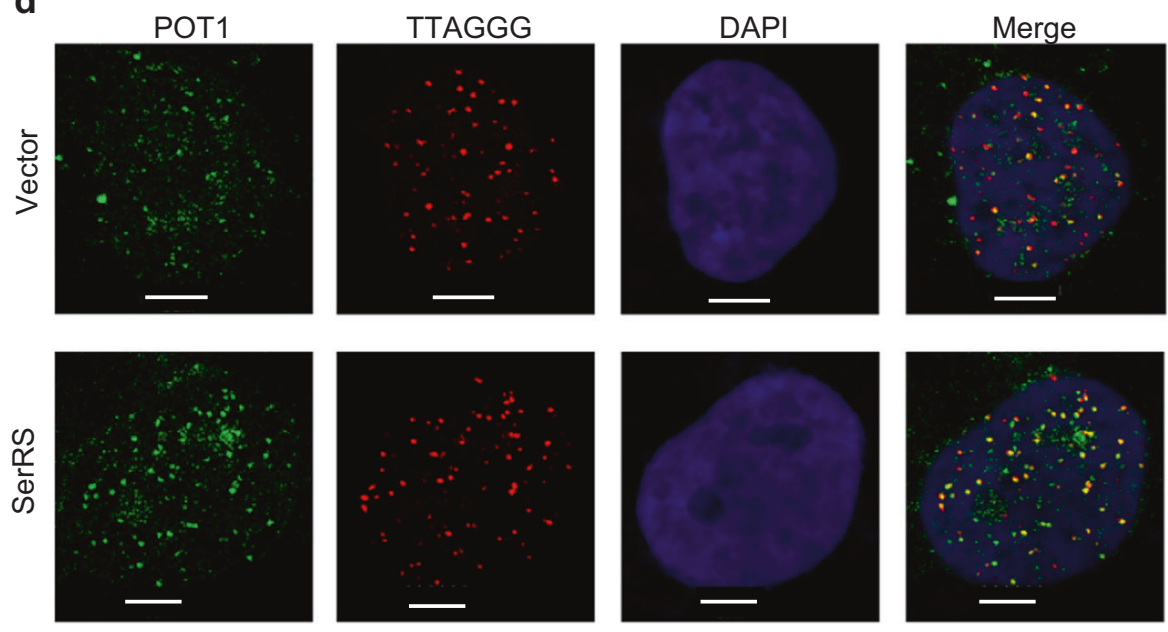

e

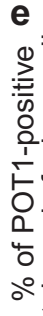

年

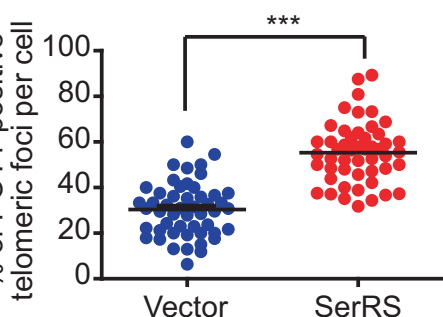

$\mathbf{f}$

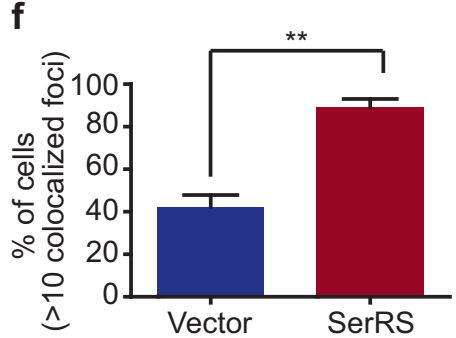

Fig. 5 SerRS promotes the recruitment of POT1 to telomeres. a Flag-tagged POT1 was transfected into HeLa 1.2.11 cells with V5-tagged SerRS or empty vectors (right panel). POT1-associated telomeric DNA fragments were immunoprecipitated with an anti-Flag antibody or a control IgG and analyzed by dot blot using DIG-labeled (CCCTAA) 6 probes (left panel). $\mathbf{b}$ Quantification of the data shown in a. Data are represented as the means \pm SEM $(n=3)$. ${ }^{* *} P<0.005$, two-tailed Student's $t$-test. c The levels of POT1 expression in SerRS-overexpressing HeLa 1.2 .11 cells as determined by immunoblot analysis. d IF-FISH showing the localization of POT1 at telomeres in HeLa 1.2.11 cells transfected with SerRS or empty vector. Cells were hybridized with Cy3-labeled (CCCTAA) 3 PNA probe (red) and immunostained with POT1 (green). Scale bars represent $5 \mu \mathrm{m}$. e Quantification of the data in $\mathbf{d}$ to show the average percentages of POT1-associated telomere foci per cell (means \pm SEM, $n=50$, ${ }^{* * *} P<0.001$, two-tailed Student's $t$-test). $\mathbf{f}$ Quantification of the data shown in $\mathbf{d}$ to show the percentages of cells with more than ten POT1-associated telomeric foci (mean $\pm \mathrm{SEM}, n=3,{ }^{* *} P<0.01$, two-tailed Student's $t$-test)

Kit (QIAGEN, Germany) and digested with a Hinf I and Rsa I enzyme mixture overnight at $37^{\circ} \mathrm{C}$. Then, each digested DNA sample was loaded onto a $0.8 \%$ agarose gel and run at $100 \mathrm{~V}$ for $3 \mathrm{~h}$. DNA was denatured, neutralized, and then blotted onto the nylon membrane (Sigma) by capillary transfer using $20 \times$ saline sodium citrate (SSC) buffer for $20 \mathrm{~h}$ at room temperature. After transfer, DNA was fixed on the wet blotting membrane by $120 \mathrm{~mJ}$ UV-crosslinking and hybridized with a DIG-labeled (CCCTAA) oligo probe in hybridization buffer overnight at $37^{\circ} \mathrm{C}$. Then, the membrane was washed and incubated with anti-DIG-AP (Roche, at 1:4000 dilution) and visualized with an imaging system, Tanon5200 (Tanon, Beijin, China). The mean TRF length can be obtained by comparing the mean sizes of the smeared bands to the molecular weight markers using the GelPro analyzer.

\section{Coimmunoprecipitation}

HeLa cells were plated in a $10-\mathrm{cm}$ dish and transiently transfected with $3 \mu \mathrm{g}$ of pFLAG-plasmid and $3 \mu \mathrm{g}$ pcDNA6C-plasmid by Lipofectamine 2000 (Invitrogen, Carlsbad, CA, USA). After $24 \mathrm{~h}$ of posttransfection, cells were lysed by sonication in IP buffer $(20 \mathrm{mM}$ Tris- $\mathrm{HCl} \mathrm{pH} \mathrm{7.5,150} \mathrm{mM} \mathrm{NaCl,} 2$ mM EDTA, 0.1\% Triton X-100 and protease inhibitor cocktail (Roche)). Immunoprecipitation was carried out by incubating the supernatants with an anti-FLAG antibody (Sigma, \#F1804, at 1:3000 dilution) or an anti-V5 
a
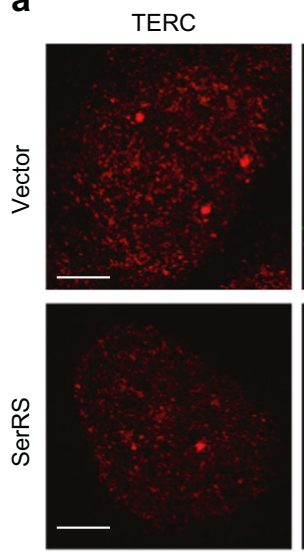

C
TRF1
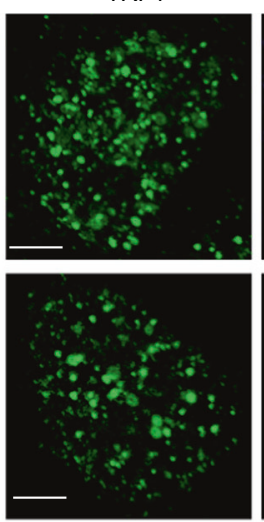

Telomere Maintenance
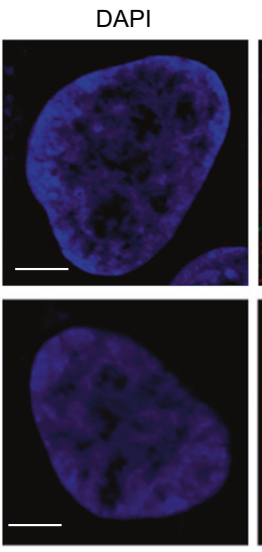
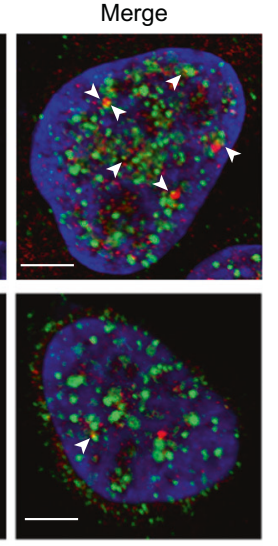

b

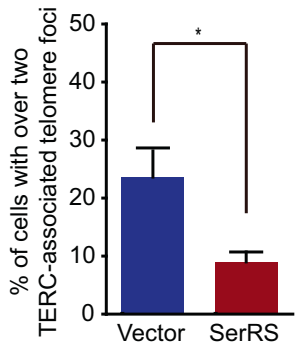

Telomere Shortening
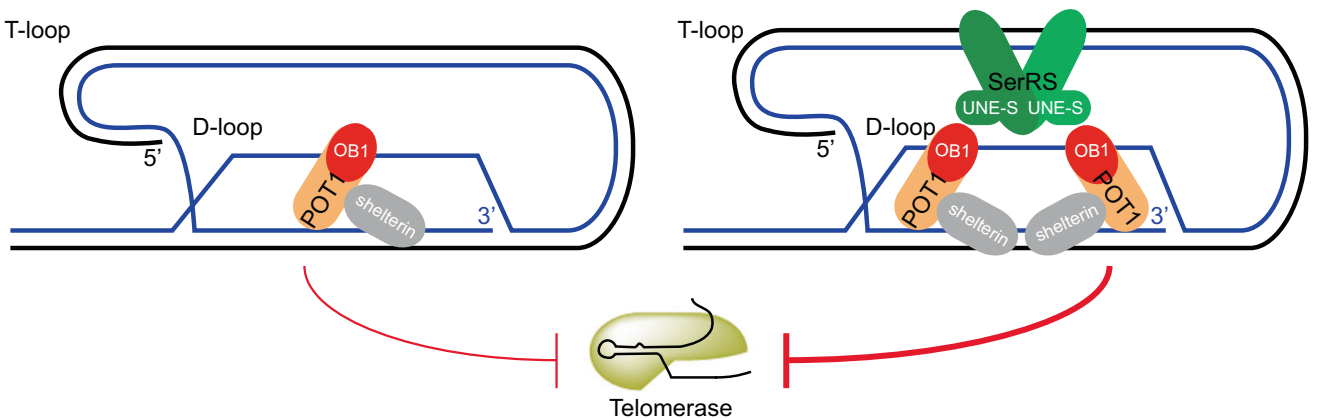

Fig. 6 SerRS prevents the recruitment of telomerase to telomeric DNA. a Telomerase RNA (TERC; red) and telomeres were visualized by RNA FISH and immunofluorescent staining with anti-TRF1 antibody (green), respectively, in HeLa 1.2.11 cells transfected with the SerRS expression vector or an empty vector. Arrows indicate telomerase foci colocalizing with telomeres. Scale bars represent $5 \mu \mathrm{m}$. b Data from a were quantified and plotted as a bar graph (means \pm SEM $, n=3,{ }^{*} P<0.05$, two-tailed Student's $t$-test). Cells with $\geq 2$ telomerase-associated foci were counted as positive, and more than 80 cells were examined for each cell line. c Model proposing a role for SerRS as a regulator of telomere length. The SerRS dimer may bind to telomeric DNA repeats, and it tethers two POT1 molecules onto a telomeric single-stranded 3'-overhang, preventing the access of telomerase and the elongation of telomere

antibody (Invitrogen, \#46-1157, at 1:3000 dilution), followed by incubation with protein $G$ agarose (Thermo-Fisher Scientific) at $4{ }^{\circ} \mathrm{C}$ overnight. After being washed three times, the recombinant proteins were eluted and detected by western blotting with an anti-FLAG antibody or an anti-V5 antibody. For the co-IP of endogenous POT1 and SerRS, $2 \mu \mathrm{g}$ of anti-POT1 antibody (Abcam, \#ab194480) and $2 \mu \mathrm{g}$ of anti-SerRS antibody were used.

\section{Protein expression and purification}

PET-20b-SerRS and pET-20b-POT1 plasmids were used to transform E. coli BL21 (DE3) cells (CWBIO, Beijing, China). The expression of recombinant proteins was induced by $1 \mathrm{mM}$ IPTG (Thermo-Fisher Scientific) for $8 \mathrm{~h}$ at $25^{\circ} \mathrm{C}$. Cells were harvested and lysed by sonication in lysis buffer $\left(50 \mathrm{mM} \mathrm{NaH}{ }_{2} \mathrm{PO}_{4} \mathrm{pH} 8.0\right.$, $300 \mathrm{mM} \mathrm{NaCl}, 10 \mathrm{mM}$ imidazole, $2 \mathrm{mg} / \mathrm{ml}$ lysozyme, protease inhibitor cocktail). The supernatants were incubated with Ni-NTA agarose beads (Qiagen) overnight at $4{ }^{\circ} \mathrm{C}$. The beads were consecutively washed with wash buffer containing $20 \mathrm{mM}$ and $40 \mathrm{mM}$ imidazole. The recombinant proteins were eventually eluted with elution buffer containing $100 \mathrm{mM}$ imidazole and were dialyzed to remove imidazole.

For the expression of GST-tagged proteins, pGEX6P-1-SerRS and pGEX6P-1-POT1 vectors were used to transform E. coli BL21 (DE3) cells. GST-tagged protein purification was carried out using glutathione agarose (Thermo-Fisher Scientific), and eluting was performed with phosphate-buffered saline (PBS) buffer containing $20 \mathrm{mM}$ reduced glutathione (Sigma-Aldrich). The purities of the recombinant proteins were assessed by SDS-PAGE electrophoresis and Coomassie blue staining. The protein concentrations were measured by NanoPhotometer (IMPLEN, Munich, Germany).

GST pulldown

GST pulldown assays were carried out, as previously described. ${ }^{29}$ Briefly, GST-fusion proteins bound to beads were incubated with $0.5 \mu \mathrm{M}$ purified recombinant proteins in $500 \mu \mathrm{l}$ of GST pulldown buffer $(150 \mathrm{mM} \mathrm{NaCl}, 20 \mathrm{mM}$ HEPES pH 7.9, $0.5 \mathrm{mM}$ EDTA, $0.1 \%$ Triton X-100, 10\% glycerol, $1 \mathrm{mM}$ DTT) overnight at $4{ }^{\circ} \mathrm{C}$. After being washed 5 times with pulldown buffer, the proteins bound to the beads were analyzed by western blot, using an anti-His (Proteintech, \#66005-1-lg, at 1:1000 dilution) or an anti-GST (Proteintech, \#10000-0-AP, at 1:1000 dilution) antibody.

Immunofluorescence (IF) and fluorescent in situ hybridization (FISH)

Cells grown on coverslips were fixed with $4 \%$ paraformaldehyde and permeabilized in $0.25 \%$ Triton $\mathrm{X}-100$ for $10 \mathrm{~min}$ at room temperature. After incubation with blocking buffer $(5 \%$ goat serum, $0.1 \%$ Tween-20, PBS) for $1 \mathrm{~h}$, cells were incubated at $4{ }^{\circ} \mathrm{C}$ overnight with anti-SerRS (made in the lab; 1:100 dilution) or antiPOT1 (Santa Cruz, CA, USA; 1:100 dilution) antibodies. Coverslips with cells were washed three times before a $1 \mathrm{~h}$ incubation at room temperature with secondary antibodies (goat anti-rabbit lgG or goat anti-mouse lgG antibodies conjugated with either Alexa488 or Alexa594). Cells were then washed and stained with 
$0.1 \mu \mathrm{g} / \mathrm{mL}$ 4,6-diamidino-2-phenylindole (DAPI, Sigma-Aldrich) and mounted onto glass slides with ProlongGold Antifade Reagent (Thermo-Fisher).

For IF staining combined with telomere FISH, after fixation, permeabilization and washing with PBS, cells were dehydrated sequentially in $70 \%, 90 \%$, and $100 \%$ ethanol for 2 min each. A Cy3OO-(CCCTAA) ${ }_{3}$ PNA telomere probe (Panagene, Korea) was added to the glass slides in hybridization buffer ( $70 \%$ formamide, $10 \mathrm{mM}$ Tris- $\mathrm{HCl} \mathrm{pH} \mathrm{7.2,} 1 \times$ blocking reagent (Roche)). After denaturation for $3 \mathrm{~min}$ at $80^{\circ} \mathrm{C}$, slides were hybridized for $2 \mathrm{~h}$ at room temperature in a humidified chamber and then washed twice with wash buffer (70\% formamide, $0.1 \%$ bovine serum albumin, $10 \mathrm{mM}$ Tris- $\mathrm{HCl} \mathrm{pH} \mathrm{7.2)} \mathrm{for} 15 \mathrm{~min}$ each and three times with PBST $(0.1 \%$ Tween 20 in PBS) for 5 min each prior to mounting and imaging.

For IF staining combined with telomerase RNA FISH, cells were fixed in $4 \%$ formaldehyde, processed in sequential dehydration solutions containing $70,90 \%$, and $100 \%$ ethanol, and then rehydrated in $2 \times$ SSC buffer with $50 \%$ formamide. Prehybridization was performed in a $2 \times \mathrm{SSC}$ solution containing $10 \%$ dextran sulfate, $2 \mathrm{mM}$ vanadyl ribonucleotide complex, $0.002 \mathrm{mg} / \mathrm{mL}$ nuclease-free BSA, $1 \mathrm{mg} / \mathrm{mL}$ E. coli tRNA, $1 \mathrm{U} / \mu \mathrm{L}$ RNasin, and $50 \%$ deionized formamide for $1 \mathrm{~h}$ at $37^{\circ} \mathrm{C}$ in a humidified chamber. For in situ hybridization, the cells were hybridized in the prehybridization solution by incubation with a mixture of three Cy3-conjugated hTERC probes ( $50 \mathrm{ng} /$ probe/sample) (Sangon Biotech, Shanghai, China) overnight at $37^{\circ} \mathrm{C}$. After washing sequentially with $50 \%$ formamide in $2 \times \mathrm{SSC}$ solution at $37^{\circ} \mathrm{C}$ and $\mathrm{PBS}$ at room temperature, the cells were incubated with a TRF1 antibody (Abcam, \#ab10570, 1:100) following the IF protocols described above.

Cell images were acquired with an Olympus FV1000 microscope (Tokyo, Japan) using a 100x objective. All image files were randomly assigned coded names to allow blinded scoring for spot colocalization and fluorescence intensity quantification. The sequences for the hTERC probes are as follows: hTERC1 $\left(5^{\prime}\right.$ GCT*GACATाITGTाGCTCAGAATGAACGGGGAAGGCGGCAGGCC GAG GCT ${ }^{*}$ T $\left.3^{\prime}\right)$, hTERC2 $\left(5^{\prime}\right.$ CT*CCGTTCCTCTTCCGCGGCCTGAAAG GCCGAACC TCGCCCCGCCCCCGAGT $\left.{ }^{*} G 3^{\prime}\right)$, hTERC3 (5' AT*GTG TGAGCCGAGCCTGGG TGCACGCCCACAGCTCAGGGAACGCGCCGC $\left.\mathrm{GCT}^{*} \mathrm{C} 3^{\prime}\right)$. The ${ }^{*}$ indicates a Cy3-conjugated T.

\section{Metaphase-FISH}

After the cell density reached $70-80 \%$ confluence, colcemid $(0.1 \mu \mathrm{g} / \mathrm{ml}$, Sigma-Aldrich) was added to the medium for $2 \mathrm{~h}$. Cells were harvested with trypsin-EDTA, washed with PBS, and resuspended in $75 \mathrm{mM} \mathrm{KCl}$ at $37^{\circ} \mathrm{C}$ for $30 \mathrm{~min}$. Then, the cells were fixed with $2 \mathrm{ml}$ of fresh cold fixative solution (methanol: acetic acid, 3:1) and mixed carefully by inverting the tube. Cells were harvested by centrifugation, and the fixation step was repeated. Finally, the cell suspension was dropped onto glass slides and incubated at $80^{\circ} \mathrm{C}$ for $3 \mathrm{~min}$; then, the glass slides were left to dry overnight. Slides were immersed in PBS for 5 min, fixed with $2 \%$ formaldehyde and dehydrated sequentially in 70,90 , and $100 \%$ ethanol for 2 min each. A Cy3-OO-(CCCTAA) ${ }_{3}$ PNA telomere probe or a FITC-OO-(CCCTAA) 3 PNA telomere probe was added to the glass slides in hybridization buffer containing $70 \%$ formamide, $10 \mathrm{mM}$ Tris $\mathrm{HCl} \mathrm{pH}$ 7.2, 1×blocking reagent and PBS. After denaturation for $3 \mathrm{~min}$ at $80^{\circ} \mathrm{C}$, slides were hybridized for $2 \mathrm{~h}$ at room temperature in a humidified chamber, washed twice with a solution of $70 \%$ formamide, $0.1 \%$ bovine serum albumin, and $10 \mathrm{mM}$ Tris- $\mathrm{HCl}$ at $\mathrm{pH} 7.2$ for $15 \mathrm{~min}$ each, and then washed three times with TBST for $5 \mathrm{~min}$ each. Glass slides were dehydrated sequentially with 70,90 , and $100 \%$ ethanol again, counterstained with $0.1 \mu \mathrm{g} / \mathrm{mL} \mathrm{DAPI}$, and then mounted onto glass slides with ProlongGold Antifade Reagent. Photos were taken using an Olympus FV1000 fluorescence microscope. The number of signal-free ends per cell in metaphase was determined by manual inspection of the same metaphase images that were used for telomere signal-intensity quantification. Statistical significance was analyzed with a two-tailed Student's $t$ test.

\section{Q-FISH}

Metaphase-FISH was performed as described above. QuantitativeFISH analysis was performed using TFL-TELO image analysis software. The distributions of fluorescence intensities, which are shown in arbitrary fluorescence units, of individual telomeres from a total of 20 cells in metaphase per treatment were displayed.

\section{Chromatin immunoprecipitation (ChIP) and Dot-blot}

ChIP was carried out using a ChIP-IT Express Enzymatic Kit (Active Motif). Briefly, cells grown to $70-80 \%$ confluence were cross-linked with $1 \%$ formaldehyde for $10 \mathrm{~min}$; crosslinking was stopped by the addition of glycine to a final concentration of $0.125 \mathrm{M}$, which was followed by incubation for $5 \mathrm{~min}$. Pellets were collected by scrapping cells and centrifuging them for $10 \mathrm{~min}$ at $2500 \mathrm{r} / \mathrm{min}$ and $4{ }^{\circ} \mathrm{C}$. After cell pellets were lysed, the nuclei pellets were resuspended in digestion buffer and incubated with $17 \mu$ of $1 \times$ enzymatic shearing cocktail at $37^{\circ} \mathrm{C}$ for $5 \mathrm{~min}$. The sheared chromatin was incubated overnight at $4{ }^{\circ} \mathrm{C}$ with $35 \mu$ of protein $\mathrm{G}$ magnetic beads and $2 \mu \mathrm{g}$ of anti-Flag antibody (Sigma-Aldrich, \#F1804) or mouse IgG (Abmart, \#B30010M) as a negative control. After washing, immunoprecipitated chromatin was eluted with elution buffer for $15 \mathrm{~min}$ and reverse-crosslinked by treatment with $5 \mathrm{M} \mathrm{NaCl}$ at $95^{\circ} \mathrm{C}$ for $15 \mathrm{~min}$. DNA was purified with RNase $\mathrm{A}$ and proteinase $\mathrm{K}$ treatment for $1 \mathrm{~h}$ at $37^{\circ} \mathrm{C}$, denatured at $95^{\circ} \mathrm{C}$ for $5 \mathrm{~min}$ and immediately placed on ice. The DNA samples were blotted using a Bio-Dot Microfiltration Apparatus (GE Healthcare, Little Chalfont, UK) and hybridized with a digoxigenin (DIG)labeled probe (Sangon Biotech, Shanghai, China) that is specific for telomeric repeats. The signal intensity was measured by GelPro software and was normalized to the signal from the input DNA on the same blot.

Electrophoretic mobility shift assay (EMSA)

EMSA was performed as Xu et al. described. ${ }^{29}$ Briefly, telomeric $[\text { TTAGGG }]_{5}$ dsDNA were synthesized, annealed, and $\left[{ }^{32} \mathrm{P}\right]$-labeled at the $5^{\prime}$ end by T4 DNA kinase (New England Biolabs) before purification using a sephadex G-25 spin column (GE Healthcare). The labeled oligonucleotides $(0.8 \mathrm{pmol})$ were incubated with recombinant SerRS at the indicated concentrations in binding buffer $(20 \mathrm{mM}$ Tris- $\mathrm{HCl}$ pH 8.0, $60 \mathrm{mM} \mathrm{KCl}, 5 \mathrm{mM} \mathrm{MgCl} 2,0.1 \mathrm{mg} / \mathrm{mL}$ BSA, $10 \mathrm{ng} / \mathrm{\mu l}$ poly (dG-dC), $1 \mathrm{mM} \mathrm{DTT})$ for $30 \mathrm{~min}$ at room temperature. The samples were loaded onto a $5 \%$ native polyacrylamide gel and underwent electrophoresis at $250 \mathrm{~V}$ in running buffer ( $25 \mathrm{mM}$ Tris $\mathrm{pH} 8.3,190 \mathrm{mM}$ glycine). Then, the gel was dried and examined by autoradiography.

Oligonucleotides used for EMSA are as follows: Telomere: $5^{\prime}$ TTAGGGTTAGGGTTAGGGTTAGGGTTAGGG $3^{\prime}$ (top strand) and $5^{\prime}$ CCCTAACCCTAACCCTAACCCTAACCCTAA $3^{\prime}$ (bottom strand); Control: $5^{\prime}$ TCGAAGTCGAAGCATGGGTCGAAGCATGGG $3^{\prime}$ (top strand) and $5^{\prime}$ CCCATGCTTCGACCCATGCTTCGACTTCGA $3^{\prime}$ (bottom strand); VEGFA promoter: 5' GGCGGGGCGGAGCCATGCGCCCCC CCCTIT $3^{\prime}$ (top strand) and $5^{\prime}$ AAAGGGGGGGGCGCATGGCTC CGCCCCGCC $3^{\prime}$ (bottom strand).

Western blot analysis

Cells were lysed in cold lysis buffer supplemented with protease inhibitor cocktail, and the lysate was subjected to SDS-PAGE. Proteins were transferred onto nitrocellulose membranes (Millipore, Billerica, MA, USA) and blotted with antibodies as follows: anti-SerRS (made in lab, 1:2000), anti-POT1 (Abcam, 1:500), antiGST (Proteintech, 1:1000), anti-Flag (Sigma, 1:3000), anti-V5 (Invitrogen, 1:3000), anti- $\beta$-actin (Santa Cruz, 1:5000), anti-P21 (Santa Cruz, 1:1000), anti-P16 (Abcam, 1:1000), and anti- $\beta$-gal (Proteintech, 1:1000). Proteins were visualized by enhanced chemiluminescent $(E C L)$ reagent (Thermo-Fisher Scientific). 
Seryl tRNA synthetase cooperates with POT1 to regulate telomere length... Li et al.

\section{ACKNOWLEDGEMENTS}

We thank Xiyun Chen, Haotian Deng and Jiaxin Wen for their help in preparing the recombinant proteins. This work was supported by grants from the National Natural Science Foundation of China (No. 81772974), the Natural Science Foundation of Tianjin City (18JCQNJC12600), the Project of Science and Technology Assistance in Developing Countries (KY201501006) and the Ph.D. Candidate Research Innovation Fund of Nankai University.

\section{AUTHOR CONTRIBUTIONS}

L.Y.X., W.L.L., L.Z., S.Y., X.R., C.X. and Y.R.C. designed experiments, analyzed data, conceptualized this project, and wrote the manuscript. L.Y.X., L.X.Y., L.Z., C.M., Y.J. and J.Y.K. performed the experiments and analyzed the data.

\section{ADDITIONAL INFORMATION}

The online version of this article (https://doi.org/10.1038/s41392-019-0078-1) contains supplementary material, which is available to authorized users.

Competing interests: The authors declare no competing interests.

\section{REFERENCES}

1. Martinez, P. \& Blasco, M. A. Replicating through telomeres: a means to an end. Trends Biochem Sci. 40, 504-515 (2015).

2. Meena, J. K. et al. Telomerase abrogates aneuploidy-induced telomere replication stress, senescence and cell depletion. EMBO J. 34, 1371-1384 (2015).

3. Holohan, B., Wright, W. E. \& Shay, J. W. Cell biology of disease: Telomeropathies: an emerging spectrum disorder. J. cell Biol. 205, 289-299 (2014).

4. Osterhage, J. L. \& Friedman, K. L. Chromosome end maintenance by telomerase. J. Biol. Chem. 284, 16061-16065 (2009).

5. Koh, C. M. et al. Telomerase regulates MYC-driven oncogenesis independent of its reverse transcriptase activity. J. Clin. Investig. 125, 2109-2122 (2015).

6. Stewart, S. A. et al. Telomerase contributes to tumorigenesis by a telomere length-independent mechanism. Proc. Natl Acad. Sci. USA 99, 12606-12611 (2002).

7. de Lange, T. Shelterin-mediated telomere protection. Annu. Rev. Genet. 52, 223-247 (2018)

8. de Lange, T. Shelterin: the protein complex that shapes and safeguards human telomeres. Genes Dev. 19, 2100-2110 (2005).

9. Palm, W. \& de Lange, T. How shelterin protects mammalian telomeres. Annu. Rev. Genet. 42, 301-334 (2008).

10. Wang, F. et al. The POT1-TPP1 telomere complex is a telomerase processivity factor. Nature 445, 506-510 (2007).

11. Nandakumar, J. \& Cech, T. R. DNA-induced dimerization of the single-stranded DNA binding telomeric protein Pot1 from Schizosaccharomyces pombe. Nucleic acids Res. 40, 235-244 (2012).

12. Lei, M., Podell, E. R. \& Cech, T. R. Structure of human POT1 bound to telomeric single-stranded DNA provides a model for chromosome end-protection. Nat. Struct. Mol. Biol. 11, 1223-1229 (2004).

13. Chen, C. et al. Structural insights into POT1-TPP1 interaction and POT1 C-terminal mutations in human cancer. Nat. Commun. 8, 14929 (2017)

14. Loayza, D. \& De Lange, T. POT1 as a terminal transducer of TRF1 telomere length control. Nature 423, 1013-1018 (2003).

15. Nandakumar, J. et al. The TEL patch of telomere protein TPP1 mediates telomerase recruitment and processivity. Nature 492, 285-289 (2012).

16. Grill, S., Tesmer, V. M. \& Nandakumar, J. The $\mathrm{N}$ terminus of the OB domain of telomere protein TPP1 is critical for telomerase action. Cell Rep. 22, 1132-1140 (2018).

17. Zhong, F. L. et al. TPP1 OB-fold domain controls telomere maintenance by recruiting telomerase to chromosome ends. Cell 150, 481-494 (2012).

18. Steffen, K. K. \& Dillin, A. A ribosomal perspective on proteostasis and aging. Cell Metab. 23, 1004-1012 (2016).

19. Curran, S. P. \& Ruvkun, G. Lifespan regulation by evolutionarily conserved genes essential for viability. PLoS Genet. 3, e56 (2007).

20. Hansen, M. et al. Lifespan extension by conditions that inhibit translation in Caenorhabditis elegans. Aging cell 6, 95-110 (2007).

21. Pan, K. Z. et al. Inhibition of mRNA translation extends lifespan in Caenorhabditis elegans. Aging cell 6, 111-119 (2007).
22. Johnson, S. C., Rabinovitch, P. S. \& Kaeberlein, M. mTOR is a key modulator of ageing and age-related disease. Nature 493, 338-345 (2013).

23. Harrison, D. E. et al. Rapamycin fed late in life extends lifespan in genetically heterogeneous mice. Nature 460, 392-395 (2009).

24. Selman, C. et al. Ribosomal protein S6 kinase 1 signaling regulates mammalian life span. Science 326, 140-144 (2009).

25. Wang, Y. P. \& Lei, Q. Y. Metabolite sensing and signaling in cell metabolism. Signal Transduct. Target Ther. 3, 30 (2018).

26. Guo, M. \& Schimmel, P. Essential nontranslational functions of tRNA synthetases. Nat. Chem. Biol. 9, 145-153 (2013).

27. Han, J. M. et al. Leucyl-tRNA synthetase is an intracellular leucine sensor for the mTORC1-signaling pathway. Cell 149, 410-424 (2012).

28. $\mathrm{Xu}, \mathrm{X}$. et al. Unique domain appended to vertebrate tRNA synthetase is essential for vascular development. Nat. Commun. 3, 681 (2012).

29. Shi, Y. et al. tRNA synthetase counteracts c-Myc to develop functional vasculature. Elife 3, e02349 (2014).

30. Fu, C. Y., Wang, P. C. \& Tsai, H. J. Competitive binding between Seryl-tRNA synthetase/YY1 complex and NFKB1 at the distal segment results in differential regulation of human vegfa promoter activity during angiogenesis. Nucleic acids Res. 45, 2423-2437 (2017).

31. Yang, G. L. \& Li, L. Y. Counterbalance: modulation of VEGF/VEGFR activities by TNFSF15. Signal Transduct. Target Ther. 3, 21 (2018).

32. Regulski, M. J. Cellular senescence: what, why, and how. Wounds 29, 168-174 (2017).

33. Buckbinder, L. et al. Induction of the growth inhibitor IGF-binding protein 3 byp53. Nature 377, 646-649 (1995).

34. Zuckerman, V., Wolyniec, K., Sionov, R. V., Haupt, S. \& Haupt, Y. Tumour suppression by p53: the importance of apoptosis and cellular senescence. J. Pathol. 219, 3-15 (2009)

35. Gyorffy, B. et al. An online survival analysis tool to rapidly assess the effect of 22,277 genes on breast cancer prognosis using microarray data of 1,809 patients. Breast cancer Res. Treat. 123, 725-731 (2010).

36. Hockemeyer, D. \& Collins, K. Control of telomerase action at human telomeres. Nat. Struct. Mol. Biol. 22, 848-852 (2015).

37. Smogorzewska, A. \& de Lange, T. Regulation of telomerase by telomeric proteins. Annu. Rev. Biochem. 73, 177-208 (2004).

38. Lee, O. H. et al. Genome-wide YFP fluorescence complementation screen identifies new regulators for telomere signaling in human cells. Mol. Cell. Proteom. 10, M110 001628 (2011)

39. Lei, M., Podell, E. R., Baumann, P. \& Cech, T. R. DNA self-recognition in the structure of Pot1 bound to telomeric single-stranded DNA. Nature 426, 198-203 (2003).

40. Rice, C. et al. Structural and functional analysis of the human POT1-TPP1 telomeric complex. Nat. Commun. 8, 14928 (2017).

41. Egan, E. D. \& Collins, K. Biogenesis of telomerase ribonucleoproteins. RNA 18, 1747-1759 (2012).

42. Schmidt, J. C., Zaug, A. J. \& Cech, T. R. Live cell imaging reveals the dynamics of telomerase recruitment to telomeres. Cell 166, 1188-11197 (2016). e1189.

43. Kim, J. H. et al. Control of leucine-dependent mTORC1 pathway through chemical intervention of leucyl-tRNA synthetase and RagD interaction. Nat. Commun. 8 732 (2017).

44. Guo, M., Yang, X. L. \& Schimmel, P. New functions of aminoacyl-tRNA synthetases beyond translation. Nat. Rev. Mol. cell Biol. 11, 668-674 (2010).

45. Baumann, P. \& Cech, T. R. Pot1, the putative telomere end-binding protein in fission yeast and humans. Science 292, 1171-1175 (2001).

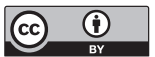

Open Access This article is licensed under a Creative Commons Attribution 4.0 International License, which permits use, sharing, adaptation, distribution and reproduction in any medium or format, as long as you give appropriate credit to the original author(s) and the source, provide a link to the Creative Commons license, and indicate if changes were made. The images or other third party material in this article are included in the article's Creative Commons license, unless indicated otherwise in a credit line to the material. If material is not included in the article's Creative Commons license and your intended use is not permitted by statutory regulation or exceeds the permitted use, you will need to obtain permission directly from the copyright holder. To view a copy of this license, visit http://creativecommons. org/licenses/by/4.0/.

(c) The Author(s) 2019 